\title{
On the incentives to increase input efficiency under monopoly trade unions
}

\author{
Tapan Biswas ${ }^{\text {a }}$, Jolian McHardy ${ }^{\text {,** }}$ \\ a Centre for Economic Policy, University of Hull, Hull HU6 7RX, UK \\ ${ }^{\mathrm{b}}$ Department of Economics, University of Sheffield, 9 Mappin Street, Sheffield SI 4DT, UK \\ Received 16 July 2003; accepted 13 February 2005 \\ Available online 24 January 2006
}

\begin{abstract}
We examine the effects of and the incentives for increasing input efficiency within a spatially segregated Cournot duopoly with monopoly trade unions whose utility functions depend on both wages and employment. We show that with neoclassical as well as Leontief technology, unions raise wages to appropriate fully the gains from labor-saving technological (or organisational) improvements, leaving the firm with no incentive to invest in increasing the efficiency of workers. However, capital-saving technological improvement may be profitable depending on the elasticity of substitution. Finally, we examine the implication of a fixed minimum wage (or competitive labor market) in one country.
\end{abstract}

(c) 2006 Elsevier B.V. All rights reserved.

JEL classification: D43; J24; J51; L13; O33

Keywords: Unions; Technological change; Cournot duopoly

\section{Introduction}

In recent years, with nations pursuing policies towards globalisation and free markets, the role of trade unions in promoting innovation and growth has come under close scrutiny. There has been a feeling that investment in improving the productivity of the workforce is less attractive to employers in the presence of strong trade unions because the benefits of such investment may be absorbed in higher wages. Where employers do face strong trade unions, investment in improving

\footnotetext{
* Corresponding author. Tel.: +44 1142 223460; fax: +44 1142223458.

E-mail address: j.mchardy@ sheffield.ac.uk (J. McHardy).
}

0167-2681/\$ - see front matter ¿ 2006 Elsevier B.V. All rights reserved. doi:10.1016/j.jebo.2005.02.004

Originally published in the Journal of Economic Behaviour and Organization 2007, 62(4), 657-669 
labor efficiency must be preceded by an understanding that employers would share the benefits of such investment. In the absence of such an understanding, strong trade unions may discourage investment in training. ${ }^{1}$

The intensity of labor training depends on many factors other than the presence of trade unions. Frazis et al. (1998, pp. 23-24) examined the determinants of training in U.S. industries and observed, "the presence of unions appears to have a negative effect on formal training... the presence of a union is predicted to reduce the proportion of time spent in formal training by 0.6 percent." The Michigan Time Study reported by Duncan and Stafford (1980) also found trade unions to have a negative effect on training. However, opinions differ on the issue. Brown (1989), for instance, cites works that find unions to have negative, positive and insignificant effects on training. Apart from training, an increase in the efficiency of labor may occur in various other ways, for example, through organisational reforms that also have financial implications for the firm. The results of this paper are therefore not restricted to any particular type of labor-saving innovation.

In contrast with a large proportion of research in this area, which is essentially empirical in nature, we address the following question: in the presence of a monopoly trade union determining the wage rate, does an improvement in the efficiency of either labor or capital benefit the producer? This problem is examined in the context of the general equilibrium setting of a Cournot/Nash duopoly, where the firms are assumed to be located in two different countries, avoiding the complications of inter-firm labor mobility. ${ }^{2}$

This paper aims to examine the desirability of labor-saving and capital-saving technological improvements from the employer's point of view in the presence of monopoly trade unions. We show that with monopoly trade unions, any gain from an improvement in labor productivity is absorbed by increased wages even if the utility of the trade union depends both on wages and the level of employment. This leaves the producers with no incentive to invest in labor training. However, an increase in capital productivity may increase the profit of the firm.

We begin by considering the case of labor-saving and capital-saving technological changes in the context of fixed coefficient (Leontief) production technology. The effects of allowing factor substitutability are then examined in Section 3. Section 4 introduces asymmetries into the analysis by first considering the case in which there is a trade union in only one of the countries and then examining the effects of a minimum wage in the other country. Section 5 concludes the paper with a summary of findings and suggestions for further research in this area.

\section{The case of fixed (Leontief) coefficient technology}

Consider a Cournot duopoly with two firms, $i$ and $j$ (each located in different countries), producing and selling a homogenous product in the international market. In order to avoid complications arising out of exchange rate fluctuations, we assume prices are denoted in a common currency. We assume a linear demand function,

$$
P=a-b Q, \quad Q=\sum Q_{t} \quad(t=i, j ; a, b>0),
$$

\footnotetext{
${ }^{1}$ Dowrick and Spencer (1994, pp. 334-337) examined the conditions under which labor-saving technological progress will be opposed by the trade unions in a Cournot duopoly with monopoly trade unions.

${ }^{2}$ Kemp et al. (1991) examined the case of an international economy with national trade unions that bargain on wages. They were mainly interested in the long-run equilibrium in a trading world. In contrast, the problem addressed here is microeconomic in nature.
}

Originally published in the Journal of Economic Behaviour and Organization 2007, 62(4), 657-669 


\section{BISWAS MCHARDY Incentives to Increase Input Efficeincy}

where $P$ is the market price and $Q_{t}$ is the quantity of output produced by the $t$ th firm using $K_{t}$ and $L_{t}$ units of capital and labor, respectively. The production coefficients are fixed, implying zero elasticity of substitution in production; thus,

$$
Q_{t} \lambda_{t}=L_{t}, \quad Q_{t} \kappa_{t}=K_{t} \quad\left(\lambda_{t}, \kappa_{t}>0\right),
$$

where $\lambda_{t}$ and $\kappa_{t}$ are the fixed labor and capital requirements of the $t$ th firm for producing one unit of output. The profit of firm $i$ is given by

$$
\pi_{i}=P Q_{i}-w_{i} L_{i}-r_{i} K_{i} .
$$

Substituting Eqs. (1) and (2) we have

$$
\pi_{i}=a Q_{i}-b Q_{i}^{2}-b Q_{i} Q_{j}-w_{i} \lambda_{i} Q_{i}-r_{i} \kappa_{i} Q_{i} .
$$

In a Cournot duopoly, each firm maximises its profit subject to a given level of its rival's output, $Q_{j}$. The equilibrium output configuration in the Cournot model is given by

$$
Q_{i}=\frac{1}{3 b}\left(a-2 w_{i} \lambda_{i}-2 r_{i} \kappa_{i}+w_{j} \lambda_{j}+r_{j} \kappa_{j}\right) .
$$

In the monopoly trade union model, wages are set by the trade unions, and the producers decide the levels of employment given the wage rates (e.g., see Addison and Chilton, 1998). We assume that the trade unions' utility functions take the Cobb-Douglas form; thus, utility for the union of firm $t$ is given $b^{3}$

$$
U_{t}=w_{t}^{\alpha_{t}} L_{t}^{1-\alpha_{t}} \quad\left(0<\alpha_{t}<1\right) .
$$

One obvious consequence of this assumption is that in setting their wages the trade unions take into account the size of employment. ${ }^{4}$ Using Eqs. (2) and (3) in Eq. (4),

$$
U_{i}=\left(\frac{\lambda_{i}}{3 b}\right)^{1-\alpha_{i}} w_{i}^{\alpha_{i}}\left(a-2 w_{i} \lambda_{i}-2 r_{i} \kappa_{i}+w_{j} \lambda_{j}+r_{j} \kappa_{j}\right)^{1-\alpha_{i}} .
$$

Given $w_{j}$, maximising $U_{i}$ with respect to $w_{i}$ gives the trade union's reaction function for $w_{i}$,

$$
w_{i}=\left(2 \lambda_{i}\right)^{-1} \alpha_{i}\left(a-2 r_{i} \kappa_{i}+w_{j} \lambda_{j}+r_{j} \kappa_{j}\right) .
$$

Solving for wages in the two firms by using the trade unions' reaction functions,

$$
w_{i}=\left(\frac{\alpha_{i}}{\lambda_{i}}\right)\left(4-\alpha_{i} \alpha_{j}\right)^{-1}\left[a\left(2+\alpha_{j}\right)-r_{i} \kappa_{i}\left(4-\alpha_{j}\right)+2 r_{j} \kappa_{j}\left(1-\alpha_{j}\right)\right] .
$$

From Eq. (6), it is clear that the unit labor cost $w_{i} \lambda_{i}$ is independent of $\lambda_{i}$. Since $r_{i}$ and $\kappa_{i}$ are fixed, the unit cost, $c_{i}=w_{i} \lambda_{i}+r_{i} \kappa_{i}$, remains the same even if $\lambda_{i}$ is smaller due to a labor-saving improvement in technology. In other words, if the productivity of labor increases, wages go up in an equal proportion so that the unit labor cost remains unchanged.

Eq. (3) may be written as

$$
Q_{i}=\frac{1}{3 b}\left(a-2 c_{i}+c_{j}\right)
$$

\footnotetext{
3 The assumption of a trade union utility function implies that with parametric changes, the wages can move in either direction.

${ }^{4}$ In the special case when a trade union seeks to maximise the total wage bill, it will set $\alpha=1 / 2$.
} 
where $c_{i}$ and $c_{j}$ are the unit costs of production for firms $i$ and $j$, respectively. Given $w_{i}$ and $r_{i}$, the unit $\operatorname{cost} c_{i}$ is also given. Since $c_{i}$ is unaffected by an increase in labor productivity, the level of output, $Q_{i}$, also remains unchanged. Consequently, the profit of firm $i$ remains unchanged. Proposition 1 follows immediately.

Proposition 1. In a segregated Cournot duopoly with monopoly trade unions, if capital and labor are perfect complements in production, the firms have no incentive to invest in on-the-job training to improve the efficiency of the workforce.

Although this neutrality result implies that wages go up after a labor-saving technological change, it also follows that the level of employment in the firm falls. From the union's point of view, whether a labor-saving technological change is welcome or not depends on the relative weight that it attaches to wages and employment in its utility function. Indeed, it is easy to show that the union prefers labor-saving technological progress if $\alpha_{t}>0.5$. To see this, multiplying Eq. (4) by $w_{t}^{\alpha-1} / w_{t}^{\alpha-1}$ and using Eq. (2), we have, $U_{t}=w_{t}^{2 \alpha_{t}-1}\left\{\left(\lambda_{t} w_{t}\right) Q_{t}\right\}^{1-\alpha_{t}}$. With labor-saving technological progress, $w_{t}$ is higher, but $w_{t} \lambda_{t}$ and $Q_{t}$ are invariant with respect to wage changes. Hence, the trade union will prefer labor-saving technological progress if $\alpha_{t}>0.5$. The trade union will oppose a labor-saving technological improvement if $\alpha_{t}<0.5$ (see Dowrick and Spencer). Therefore, in the case of $\alpha_{t} \leq 0.5$, it follows that neither the firm nor the trade union is interested in labor-saving technological improvements (even if they come at zero cost). This is indeed a remarkable result. Clearly, the firm is uninterested in productivity investment because all the gains are expropriated by the union. However, given the unions' preferences over wages and employment, even if they expropriate the full gains from the productivity improvement in terms of increased wages, this is insufficient to compensate for the loss in employment. The only group gaining from such a technological improvement would be those workers who avoid the cull and enjoy higher wages.

So far we have established that in the fixed-coefficients model, for $\alpha_{t}>0.5$, though the union welcomes a labor-saving change in technology, the producer is not interested in investing for it. In Section 3, we see that this neutrality result (with respect to the unit cost, profit and the quantity of output produced) holds even if we assume factor substitutability, provided constant returns to scale in production holds.

Note that if the trade union agrees to share the gains from labor-saving technological innovation with the firm, then the introduction of such innovations may be profitable for the firm. For example, if we assume a Nash-bargaining scenario where the wage rate is decided through a bargain between the firm and the union (Calabuig and Gonzalez-Maestre, 2002), a firm may have an incentive to introduce a labor-saving technology.

Turning to the productivity of capital, from Eq. (6) it is obvious that an increase in the productivity of capital (a reduction in $\kappa_{i}$ ) due to capital-saving technological progress will increase $w_{i}$, and consequently the labor cost per unit of output, $w_{i} \lambda_{i}$, will increase. However, from Eq. (6) we have

$$
\frac{\mathrm{d}\left(w_{i} \lambda_{i}\right)}{\mathrm{d}\left(r_{i} \kappa_{i}\right)}=-\frac{\alpha_{i}\left(4-\alpha_{j}\right)}{4-\alpha_{i} \alpha_{j}}>-1 .
$$

Since $\mathrm{d}\left(r_{i} \kappa_{\mathrm{i}}\right)<0$, we have $\mathrm{d}\left(w_{i} \lambda_{i}\right)+\mathrm{d}\left(r_{i} \kappa_{i}\right)<0$, implying that capital-saving technological progress in firm $i$ must cause the unit cost, $c_{i}$, to fall. Such progress will be welcomed by firm $i$ since a reduction in firm $i$ 's unit cost increases both its output and its profit. Proposition 2 follows immediately.

Originally published in the Journal of Economic Behaviour and Organization 2007, 62(4), 657-669 


\section{BISWAS MCHARDY Incentives to Increase Input Efficeincy}

Proposition 2. In a segregated Cournot duopoly with monopoly trade unions, if capital and labor are perfect complements in production, the firms have an incentive to invest in capitalsaving technological progress.

These findings support the common belief that in the presence of a strong union, employers have a greater incentive to invest in capital-saving technological change than to improve the skills of the workers. The employers consider the discounted stream of increased profits and introduce the new technology only if this exceeds the associate cost.

\section{The case of neoclassical technology}

We assume, as before, a linear demand function given by Eq. (1). However, in order to accommodate factor substitutability we assume that the production functions exhibit constant returns to scale with well-known neoclassical properties,

$$
Q_{t}=F\left(A_{t} L_{t}, B_{t} K_{t}\right) \quad(t=i, j)
$$

where $A_{t} L_{t}$ and $B_{t} K_{t}$ are, respectively, the quantities of labor and capital employed, measured in efficiency units. To start with, let $A_{t}$ and $B_{t}=1$, so that one unit of an efficient factor of production is equivalent to one physical unit of the same factor of production. With constant returns to scale, given the wage rate $w_{t}$ and rental $r_{t}$, the unit cost, $c_{t}$, is constant. ${ }^{5}$ Clearly $c_{t}$ may be expressed as

$$
c_{t}=\frac{w_{t} l_{t}}{s_{t}}
$$

where $l_{t}$ is the quantity of labor used to produce one unit of output and $s_{t}\left(=w_{t} l_{t} /\left(w_{t} l_{t}+r_{t} k_{t}\right)\right)$ is the share of wages in the unit cost.

As in the previous section, we are assuming a Cournot duopoly where the Cournot-Nash solution in outputs is given by Eq. (7) and the demand for labor is given by

$$
L_{i}=l_{i} Q_{i}=\frac{1}{3 b}\left(a l_{i}-2 c_{i} l_{i}+c_{j} l_{i}\right)
$$

We also assume that the unions' utility functions are of the Cobb-Douglas form as in Eq. (4). Substituting $L_{i}$ from Eq. (10) into Eq. (4), we have

$$
U_{i}=\left(\frac{1}{3 b}\right)^{1-\alpha_{i}} w_{i}^{\alpha_{i}}\left(a l_{i}-2 c_{i} l_{i}+c_{j} l_{i}\right)^{1-\alpha_{i}} .
$$

Maximising Eq. (11) with respect to $w_{i}$ yields, after some manipulation, the following first order condition:

$$
\alpha_{i} l_{i}\left(a-2 c_{i}+c_{j}\right)+\left(1-\alpha_{i}\right) w_{i} \frac{\mathrm{d} l_{i}}{\mathrm{~d} w_{i}}\left(a-2 c_{i}+c_{j}\right)-2 l_{i} \frac{\mathrm{d} c_{i}}{\mathrm{~d} w_{i}}\left(1-\alpha_{i}\right) w_{i}=0 .
$$

\footnotetext{
5 Note that in equilibrium (after adjustments in employment) the factors are paid according to their marginal revenue productivity (=marginal revenue $\times$ marginal physical productivity). However, the wage-rental ratio $(\omega)$ is given by the ratio of marginal physical products.
}

Originally published in the Journal of Economic Behaviour and Organization 2007, 62(4), 657-669 
Since the firms are minimising unit costs, from the properties of the minimum cost function (see McKenzie, 1957) we know that

$$
\frac{\mathrm{d} c_{i}}{\mathrm{~d} w_{i}}=l_{i}
$$

Substituting Eq. (13) in Eq. (12) and rearranging we get

$$
\left(a-2 c_{i}+c_{j}\right)\left\{\alpha_{i} l_{i}+\left(1-\alpha_{i}\right) w_{i} \frac{\mathrm{d} l_{i}}{\mathrm{~d} w_{i}}\right\}-2 l_{i}^{2}\left(1-\alpha_{i}\right) w_{i}=0 .
$$

Dividing through by $l_{i}$,

$$
\left(a-2 c_{i}+c_{j}\right)\left\{\alpha_{i}+\left(1-\alpha_{i}\right) \eta_{i}\right\}-2\left(1-\alpha_{i}\right) w_{i} l_{i}=0,
$$

where $\eta_{i}$ is firm $i$ 's elasticity of demand for labor at the unit level of output. Eq. (14) is the implicit reaction function $\left(R_{i}\right)$ of firm $i$ 's trade union, given $c_{j}$.

We are dealing with comparative static results, and hence the existence of a unique and stable solution is essential. A necessary first step in verifying this involves re-specifying the reaction function (14) using (15), which follows (see Biswas and McHardy, 2003). In equilibrium, the relationship (15) holds between the (compensated) elasticity of demand for labor in firm $t, \eta_{t}$, and the elasticity of substitution, $\sigma_{t}$, between labor and capital and the share of wages in the unit cost (equal to the share of total wages in the total cost) for firm $t, s_{t}: 6$

$$
\eta_{t}=\left(1-s_{t}\right) \sigma_{t} .
$$

Using Eqs. (14) and (15), we have,

$$
\left(a-2 c_{i}+c_{j}\right)\left\{\alpha_{i}+\left(1-\alpha_{i}\right)\left(1-s_{i}\right) \sigma_{i}\right\}-2\left(1-\alpha_{i}\right) w_{i} l_{i}=0 .
$$

Using Eq. (9) in Eq. (16) and re-arranging, the reaction function for firm $i$ may be expressed as

$$
c_{i}=\frac{1}{2}\left(a+c_{j}\right)\left[\frac{1}{1+\frac{s_{i}\left(1-\alpha_{i}\right)}{\alpha_{i}+\left(1-\alpha_{i}\right)\left(1-s_{i}\right) \sigma_{i}}}\right] .
$$

Proposition 3. If the reaction functions $R_{i}$ and $R_{j}$ are continuous, an equilibrium solution of the trade union bargaining model with factor substitutability exists. The equilibrium is unique and stable. $^{7}$

Having established that the model has the usual desirable properties for comparative static analysis, we now consider the effects of labor-saving and capital-saving technical improvements on profit. The following proposition is parallel to Proposition 1.

Proposition 4. In a segregated Cournot duopoly with monopoly trade unions, if the production functions are subject to constant returns to scale, the benefits of labor-saving technological

\footnotetext{
${ }^{6}$ As an example, let us consider the simple case of a Cobb-Douglas production function: $Q=A K^{1-b} L^{b}$. According to Eq. (15), the (compensated) elasticity of demand for labor is $\eta=(1-b)$. In consumer theory, if the utility function is of the Cobb-Douglas type the elasticity of demand is 1 . This is because, apart from the substitution effect, there is also the income effect. However, in production theory, the income effect is zero; thus, the factor demand curve is a compensated demand curve. Therefore, the elasticity of demand for labor is $(1-b)$.

7 The Proof of Proposition 3 and all subsequent propositions (except 5) are given in Appendix A which is available on the JEBO website.
}

Originally published in the Journal of Economic Behaviour and Organization 2007, 62(4), 657-669 


\section{BISWAS MCHARDY Incentives to Increase Input Efficeincy}

progress will be fully absorbed in wage increases so that the unit cost, profit and the quantity of output produced will remain unaltered: firms will have no incentive to invest in improving the productivity of the workforce.

According to Proposition 4, a labor-saving technological change in firm $i$ does not affect the reaction function $R_{i}$; hence, the equilibrium is also unaffected.

Let us now study the effect of capital-saving technological progress where a smaller amount of new capital is as productive as that of the original quantity of old capital. Capital-saving technological progress implies that given the same wage-rental ratio, the capital-labor ratio (capital measured in terms of efficiency) will be higher per unit output. ${ }^{8}$

Of course, a firm will introduce capital-saving technological improvements only if they are profitable. Therefore, in Eq. (8) an increase in $B_{t}$ (capital-saving technological progress) must still be profitable for the firm after taking into account the revised wage demands of the trade union. In what follows, in the context of capital-labor substitutability and monopoly trade unions, we shall show that whether capital-saving technological progress is or is not profitable for the firm depends on the elasticity of substitution.

\subsection{The case of Cobb-Douglas production technology}

Since rental is given, an increase in the efficiency of capital implies that the cost of a unit of efficient capital has fallen. Provided the wage rate does not increase, if the firm wishes to employ the same amount of labor with the same amount of efficient capital (less physical capital) to produce one unit of output, the unit cost will be lower. However, the trade union may decide to set a higher wage rate. For example, let the production function be of the Cobb-Douglas type: $Q_{t}=\bar{A}_{t} L_{t}^{\beta_{t}} K_{t}^{1-\beta_{t}}$. In this case, $s_{t}=\mathrm{MR}_{t}\left(\mathrm{MPL}_{t} l_{t}\right) /\left(\mathrm{MR}_{t}\left(\mathrm{MPL}_{t} l_{t}+\mathrm{MPK}_{t} k_{t}\right)\right)=\beta_{t}$, and $\sigma_{t}=1$, where $\mathrm{MR}_{t}, \mathrm{MPL}_{t}$ and $\mathrm{MPK}_{t}$ are, respectively, the marginal revenue, marginal productivity of labor and marginal product of capital for firm $t$. Since $\beta_{t}$ and $\sigma_{t}$ are independent of wages and rental, then the right hand side in Eq. (17) is also invariant with respect to wages and rental. Therefore, to restore the balance in Eq. (17) following the fall in $c_{i}$ due to labor-saving or capitalsaving technological progress, the trade union will ask for a higher wage so that the unit cost remains unaltered. Proposition 5 follows immediately.

Proposition 5. In a segregated Cournot duopoly with monopoly trade unions, if the production function is of the Cobb-Douglas type, no matter what variety of technological progress takes place, all the benefits of the technological progress will be absorbed in higher wages by the monopoly trade union, so the firm has no incentive to invest in improving the productivity of capital.

\subsection{The case of CES production technology}

We have seen that capital-saving technological progress increases the profitability of a firm in the case of fixed coefficients $(\sigma=0)$, but has no effect on profitability where the production functions are Cobb-Douglas $(\sigma=1)$. We now examine the case of $0<\sigma<1$. We assume a constant

\footnotetext{
${ }^{8}$ In the growth literature, technological progress induced by an increase in the efficiency of labor (capital) is known as labor (capital) augmenting technological progress.
}

Originally published in the Journal of Economic Behaviour and Organization 2007, 62(4), 657-669 
elasticity of substitution (CES) production function to keep the problem solvable, thus,

$$
Q_{t}=\bar{A}_{t}\left[\gamma_{t}\left(B_{t} K_{t}\right)^{-\rho}+\beta_{t}\left(A_{t} L_{t}\right)^{-\rho}\right]^{-1 / \rho} \quad 0<\sigma=\frac{1}{1+\rho}<1 .
$$

Our assumption, $\sigma<1$, implies $\rho>0$. Since we are considering changes in capital productivity here, the productivity of labor is assumed to remain the same, that is, $A_{t}=1$. In this case, given Eq. (18), the share of wages in the unit cost turns out to be

$$
s_{t}=\beta_{t}\left(\bar{A}_{t} l_{t}\right)^{-\rho} \text {. }
$$

Before we proceed further, we note that in the reaction function $R_{i}$ given by Eq. (17), only the variable $c_{j}$ from firm $j$ affects $c_{i}, s_{i}$ and all other variables in firm $i$. Similarly, $R_{j}, c_{j}, s_{j}$ and all other variables in firm $j$ are affected only by $c_{i}$ in firm $i$. Hence, along the reaction function $R_{j}, c_{j}$ will be affected only by capital-saving technological progress in firm $i$ if $c_{i}$ is affected. For example, if the trade unions increase $w_{i}$ in a way that $c_{i}$ is unaffected, then the technological change in firm $i$ will not have any impact on $c_{j}$.

Proposition 6. With CES production technology and $\sigma<1$, if a capital-saving technological improvement takes place in firm $i$, the reaction function $R_{i}$ will shift to the left, leading to smaller unit costs $c_{i}$ and $c_{j}$ in equilibrium.

In the case of $\sigma<1$, we can only say that given $c_{j}, c_{i}$ will decrease with technological progress. However, we cannot say whether the wage rate $w_{i}$ will increase or decrease.

The case of $\sigma>1$ (i.e., $\rho<0$ ) is too difficult to analyse at this level of generality because of the difficulty in predicting the direction in which the trade union will change the wage rate: hence we cannot predict the direction in which $R_{i}$ will shift. However, this case is also uninteresting for two reasons. First, in the context of CES production technology, $\sigma>1$ implies the possibility that output can be produced either by labor or by capital alone. Second, empirically this is an unusual case. Rowthorn (1999) contains estimates of the elasticity of substitution for several European countries, the U.S., Australia, Canada and Japan. Except for the spurious case of Canada, the estimates of $\sigma$ for all other countries are significantly below 1 .

Proposition 7. With CES production technology and $\sigma<1$, the introduction of capital-saving technological progress in firm $i$ increases the profit of firm $i$ and reduces the profit of firm $j$.

Proposition 7 implies that if the constant returns to scale production function of firm $i$ is of the CES type with the elasticity of substitution being less than 1, investment in capital-saving technological improvement, through the use of more efficient capital inputs, increases the profit of the firm. On the other hand, by Proposition 4, labor-saving technological progress, due to improved efficiency of labor through training, does not change the profit of the firm because the gain in profit is eaten away by an increase in the wage rate set by the trade union.

\section{Asymmetric union power and minimum wages}

The role of interdependency that characterises the Cournot model is important to note. Suppose the labor market for firm $j$ is perfectly competitive with a constant wage, $w_{j}$. In this case the unit cost, $c_{j}$, is constant, and the reaction function, $R_{j}$, is horizontal to the $c_{i}$-axis (see Fig. 1). If $\sigma_{i}<1$, an increase in the productivity of labor will shift the reaction function from $R_{i}$ to $R_{i}^{\prime}$. The unit cost $c_{i}$ will drop to $c_{i}^{\prime}$ if firm $i$ has a monopoly trade union but firm $j$ does not. On the other hand, if firm $j$ also has a monopoly trade union, $c_{i}$ will drop to $c_{i}^{\prime \prime}$ with the improvement in labor productivity.

Originally published in the Journal of Economic Behaviour and Organization 2007, 62(4), 657-669 


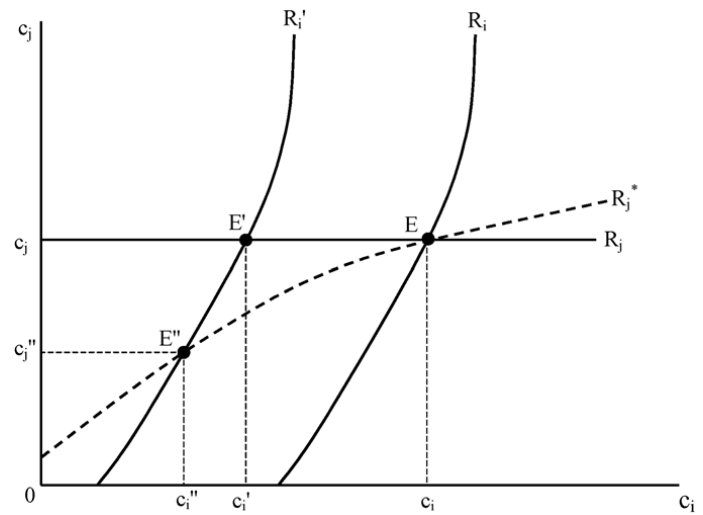

Fig. 1. Equilibrium under asymmetric input market structure.

From firm $i$ 's point of view, the benefit from increased labor productivity is higher if firm $j$ has a monopoly trade union. The reason is simple. A reduction in $c_{i}$ will have an adverse effect on output and employment in firm $j$, causing the trade union for firm $j$ to reduce its wage rate. This will trigger a retaliatory cut in $w_{i}$ and result in a further reduction in $c_{i}$. In the absence of a drop in $c_{j}$, there will be a smaller reduction in $c_{i}$.

This observation has an interesting implication for regulatory minimum wages (which are usually analysed in the domestic context) in the international context. Suppose, in country $j$, there is a regulatory minimum wage. This implies that the reaction function $R_{j}$ is horizontal to the $c_{i}$-axis as in Fig. 1. A capital-saving technological improvement in country $i$ does not affect $c_{j}$ but reduces $c_{i}$ by an amount $\left(c_{i}-c_{i}^{\prime}\right)$, which is less than $\left(c_{i}-c_{i}^{\prime \prime}\right)$. It is easy to show that in this case, the profit of firm $i$ will be less than if wages were flexible. On the other hand, the profit for firm $j$ will be higher (will fall less) than if wages were flexible. Note,

$$
\pi_{i}=\frac{1}{9 b}\left(a-2 c_{i}+c_{j}\right)^{2}, \quad \pi_{j}=\frac{1}{9 b}\left(a-2 c_{j}+c_{i}\right)^{2} .
$$

In the case of a downwardly rigid wage (binding minimum wage) in firm $j$,

$$
\Delta \sqrt{\pi_{i}}=-\Delta c_{i} \sqrt{\frac{4}{9 b}}=\left(c_{i}-c_{i}^{\prime}\right) \sqrt{\frac{4}{9 b}}, \quad \Delta \sqrt{\pi_{j}}=\Delta c_{i} \sqrt{\frac{1}{9 b}}=-\left(c_{i}-c_{i}^{\prime}\right) \sqrt{\frac{1}{9 b}},
$$

where $c_{i}$ and $c_{i}^{\prime}$ are the values of $c_{i}$ associated with equilibria $E$ and $E^{\prime}$ in Fig. 1 (note, $\Delta c_{i}$ is negative). When wages are flexible in firm $j$ (i.e., trade unions are willing to accept a lower real wage in order to avoid unemployment),

$$
\begin{aligned}
& \Delta \sqrt{\pi_{i}}=-\Delta c_{i} \sqrt{\frac{4}{9 b}}+\Delta c_{j} \sqrt{\frac{1}{9 b}}=\left[\left(c_{i}-c_{i}^{\prime}\right)+\left(c_{i}^{\prime}-c_{i}^{\prime \prime}\right)\right] \sqrt{\frac{4}{9 b}}-\left(c_{j}-c_{j}^{\prime \prime}\right) \sqrt{\frac{1}{9 b}}, \\
& \Delta \sqrt{\pi_{j}}=-\Delta c_{j} \sqrt{\frac{4}{9 b}}+\Delta c_{i} \sqrt{\frac{1}{9 b}}=\left[\left(c_{i}-c_{i}^{\prime}\right)+\left(c_{i}^{\prime}-c_{i}^{\prime \prime}\right)\right] \sqrt{\frac{1}{9 b}}+\left(c_{j}-c_{j}^{\prime \prime}\right) \sqrt{\frac{4}{9 b}} .
\end{aligned}
$$

Originally published in the Journal of Economic Behaviour and Organization 2007, 62(4), 657-669 
From Eq. (17) and the Proof of Proposition 3, $c_{j}>2 c_{i}-a$. Therefore, $\left(c_{j}-c_{j}^{\prime \prime}\right)>2\left(c_{i}^{\prime}-c_{i}^{\prime \prime}\right)$, the profit of firm $i$ will be smaller and the profit of firm $j$ will be larger (will fall less) under flexible wages than when firm $j$ faces a minimum wage regime. The reason lies with the interdependency of firm wages. Under a binding regulatory minimum wage in firm $j$, if a capital-saving technological improvement takes place in firm $i$, the drop in the wage in firm $i$ will be smaller and it works out that the profit of the firm will be lower.

\section{Concluding remarks}

In this paper, we considered a modified Cournot duopoly model with spatially segregated firms each of whom faces a monopoly trade union. We have shown that if production coefficients are fixed or the production functions are subject to constant returns to scale, labor-saving technological improvements in a firm will only increase the wage rate set by its trade unions and will have no effect on other variables (notably, the profit of the firm) in the system. Hence, the firm has no incentive to invest in making its workers more productive. On the other hand, the introduction of capital-saving technological improvement in a firm may increase its profit. Hence, in a regime of monopoly trade unions, the firms should be interested in capital-saving rather than in labor-saving improvements. Interdependence in the wage setting process by the trade unions is important. If there is a binding regulatory minimum wage in one country or the labor market in that country is competitive, then it transmits a degree of inflexibility in wages to the other country. If any capital-saving technological improvement takes place in the firm in the other country, its effect on profit will be reduced because of a smaller reduction in wages.

This paper uses the framework of non-co-operative games. Hence, in the presence of monopoly trade unions, no investment in labor training is carried out. As a result, the workers as well as the employers suffer. This calls for co-operation in restraining the increase in wages. A firm must agree (or have an understanding) with the trade union on a scheme of wage settlement before it decides to install a scheme of labor training. Such co-operative behaviour seems to exist in many industrialised countries such as Germany and Japan. Even if both parties agree on a scheme, what is the guarantee that the trade unions will stick to their commitment? Note that investment in labor training is an on-going process and employers can discontinue their expenditure on labor training at any time if the unions do not keep to their promises. Hence, the co-operative game is played repeatedly. Given any time-discount rate, there must exist a suitable threat strategy that will support the co-operative agreement. In the context of investment in physical capital, several authors have addressed the question of stability of the co-operative solution in wage settlement. ${ }^{9}$ However, for the government, rather than rely upon the possibility of co-operation between firms and unions, it may be desirable to adopt a policy of influencing the monopoly trade unions so that they do not expropriate all the gains from improvements in labor productivity.

Finally, in this paper, we assumed that all the agents in the model have perfect information. A firm and its trade union in one country may not know that the firm in the other country has been able to reduce its costs unless the other firm reveals its technology through taking patents, but the other firm may not be interested in taking patents because the period of patenting is too short. An interesting area of further research would be to explore firms' strategies under asymmetric cost information.

${ }^{9}$ For example, see Baldwin (1983), Espinosa and Rhee (1989) and Addison and Chilton.

Originally published in the Journal of Economic Behaviour and Organization 2007, 62(4), 657-669 


\section{BISWAS MCHARDY Incentives to Increase Input Efficeincy}

\section{Acknowledgements}

The authors would like to thank John Addison and Roy Ruffin for useful discussions, the associate editor and the anonymous referees of this journal for useful comments and suggestions. However, the responsibility for any errors lies with the authors.

\section{Appendix A}

Proof of Proposition 3. Using Eq. (17), the equation of $R_{i}$ may be written as $2 c_{i}=\left(a+c_{j}\right) \xi_{i}$ (where $0<\xi_{i}<1$ ), or, $c_{j}=2 c_{i} / \xi_{i}-a$. Therefore, $c_{j}>2 c_{i}-a$, and the reaction function of firm $i$ $\left(R_{i}\right)$ starts from the point $\left(a \xi_{i} / 2,0\right)$. Using a similar argument, the reaction function $R_{j}$ starts from the point $\left(0, a \xi_{j} / 2\right)$ and $c_{i}>2 c_{j}-a$. The reaction functions $R_{i}$ and $R_{j}$ with values of $c_{i}$ and $c_{j}$ that satisfy the conditions: (i) $c_{i}, c_{j}>0$, (ii) $c_{j}>2 c_{i}-a$ and (iii) $c_{i}>2 c_{j}-a$ are bounded and continuous. Hence, a solution must exist. The intercepts of $R_{i}$ and $R_{j}$ with the $c_{i}$-axis and the $c_{j}$-axis, respectively, are positive. Also note that since $\xi_{i}$ and $\xi_{j}$ are less than 1 , the slopes of $R_{i}$ and $R_{j}$ with respect to the $c_{i}$-axis are greater than 2 and less than $1 / 2$, respectively (see Fig. 2). At the point of intersection, $R_{i}$ must intersect $R_{j}$ from below. Hence, the equilibrium is unique and stable.

Proof of Proposition 4. Let $\left(w_{i}^{*}, l_{i}^{*}, w_{j}^{*}, l_{j}^{*}\right)$ be the solution obtained by solving Eq. (14) simultaneously for $i$ and $j$. A labor-saving technological change in firm $i$ implies that, in Eq. (8), $A_{i}$ increases from 1 to $1+\delta$ (where $\delta>0$ ). If the wage rate per unit of physical labor is multiplied by $1+\delta$, the wage per unit of efficient labor remains the same as before. Note that Eq. ( 8 ) is unaffected except that $A_{i}$ has a higher value. Given the same efficiency wage and rental, the firm will employ the same amounts of efficient labor and capital per unit of output (i.e., the firm $i$ will employ $l_{i} /(1+\delta)$ units of physical labor per unit of output). Hence, the unit labor cost is unaffected. Since the firm also employs the same amount of capital, the unit cost remains the same. By Eq. (7), the same amount of output will be produced, implying the same amount of profit for firm

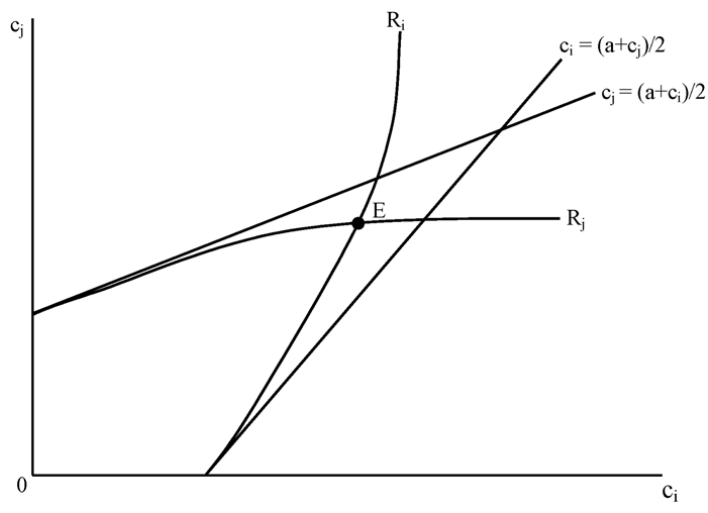

Fig. 2. The equilibrium.

Originally published in the Journal of Economic Behaviour and Organization 2007, 62(4), 657-669 
$i$. Eq. (14) is also satisfied with the same wage per unit of efficient labor because both the labor $\operatorname{cost}, w_{i} l_{i}$, and $\eta_{i}$ remain the same. The elasticity of demand for efficient labor remains the same because the efficient wage is the same and the unit isoquant, in terms of efficient inputs, is the same. Furthermore, the elasticity of demand for physical labor $\left(\eta_{i}\right)$ with respect to the wage paid to physical labor is the same as the elasticity of demand for efficient labor.

Proof of Proposition 6. Suppose $R_{i}$ does not shift to the left (i.e., for a particular value of $c_{j}$, $c_{i}$ is higher or the same on the reaction function $R_{j}$ ). However, given the same wage rate $w_{i}$, the capital-saving technological improvement must reduce $c_{i}$. Therefore, the only reason for $c_{i}$ to be higher or the same is that the trade union has set $w_{i}$ at a higher level. With capital-saving technological progress, a higher wage rate implies that $l_{i}$ is lower for two reasons. First, given the same $w_{i}, l_{i}$ is lower due to capital-saving technological progress. Second, $l_{i}$ is lowered further by the increase in $w_{i}$. Since, $\rho>0$ by assumption, Eq. (19) implies that $s_{i}$ is higher. By Eq. (17), given $c_{j}=w_{j} l_{j} / s_{j}, c_{i}$ must have a lower value if $s_{i}$ is higher. Thus, the proposition is proved by contradiction.

Proof of Proposition 7. The profit of the firm $i$ is given by

$$
\pi_{i}=\left(P-c_{i}\right) Q_{i}=\left[a-b\left(Q_{i}+Q_{j}\right)-c_{i}\right] Q_{i}=\frac{1}{9 b}\left(a-2 c_{i}+c_{j}\right)^{2} .
$$

Profit, $\pi_{i}$, will increase if $-2 \Delta c_{i}>\Delta c_{j}$. In view of Proposition 3, a capital-saving technological improvement implies that both $\Delta c_{i}$ and $\Delta c_{j}$ are negative. Hence, $\pi_{i}$ will increase if $2\left|\Delta c_{i}\right|>\left|\Delta c_{j}\right|$. By Proposition $3, R_{i}$ shifts to the left implying that the equilibrium moves to the left along the reaction function $R_{j}$. Since, the slope of $R_{j}$ is less than $1 / 2$ everywhere, $\left|\Delta c_{i}\right|>\left|\Delta c_{j}\right|$. Hence, $\pi_{i}$ must increase. The profit of firm $j$ is given by

$$
\pi_{j}=\frac{1}{9 b}\left(a-2 c_{j}+c_{i}\right)^{2}
$$

hence, $\Delta \pi_{j}$ is positive if $2\left|\Delta c_{j}\right|>\left|\Delta c_{i}\right|$. Since, the slope of $R_{j}$ is less than $1 / 2$ everywhere, $2\left|\Delta c_{j}\right|>\left|\Delta c_{i}\right|$. Hence, $\pi_{j}$ must decrease.

\section{References}

Addison, J.T., Chilton, J.B., 1998. Self-enforcing union contracts: efficient investment and employment. Journal of Business 71, 349-369.

Baldwin, C.Y., 1983. Productivity and labor unions: an application to the theory of self-enforcing contracts. Journal of Business 56, 155-185.

Biswas, T.K., McHardy, J.P., 2003. The long-run effect of a wage policy on employment. Journal of Policy Modelling 25, 267-273.

Brown, C., 1989. Empirical evidence on private training. Commission on Workforce Quality and Labor Market Efficiency. Investing in People, vol. 1. Department of Labor, Washington, DC, pp. 301-329.

Calabuig, V., Gonzalez-Maestre, M., 2002. Union structure and incentives for innovation. European Journal of Political Economy 18, 177-192.

Dowrick, S., Spencer, B.J., 1994. Union attitudes to labor-saving innovation: when are unions Luddites? Journal of Labor Economics 12, 316-344.

Duncan, G., Stafford, F.P., 1980. Do union members receive compensating wage differentials? American Economic Review 70, 355-371.

Espinosa, M.P., Rhee, C., 1989. Efficient wage bargaining as a repeated game. Quarterly Journal of Economics 104, $565-588$.

Frazis, H., Gittleman, M., Joyce, M., 1998. Determinants of Training: An Analysis Using Both Employer and Employee Characteristics. Bureau of Labor Statistics, Washington.

Originally published in the Journal of Economic Behaviour and Organization 2007, 62(4), 657-669 
Kemp, M.C., Van Long, N., Shimomura, K., 1991. Labour Unions and the Theory of International Trade. North-Holland, New York.

McKenzie, L., 1957. Demand theory without a utility index. Review of Economic Studies 24, 185-189.

Rowthorn, R., 1999. Unemployment, wage bargaining and capital labour substitution. Cambridge Journal of Economics $23,413-425$.

Originally published in the Journal of Economic Behaviour and Organization 2007, 62(4), 657-669 